\title{
Study on the Scientific and Technological Transformation Mechanism in Universities
}

\author{
Duanyang Ren, Wei Song, Yuan Ni \\ School of Public Affairs, University of Science and Technology of China, Hefei, China \\ Email: rdy@mail.ustc.edu.cn
}

How to cite this paper: Ren, D.Y., Song, W. and Ni, Y. (2017) Study on the Scientific and Technological Transformation Mechanism in Universities. Open Journal of Social Sciences, 5, 271-285. https://doi.org/10.4236/jss.2017.56023

Received: May 26, 2017

Accepted: June 25, 2017

Published: June 28, 2017

Copyright (c) 2017 by authors and Scientific Research Publishing Inc. This work is licensed under the Creative Commons Attribution International License (CC BY 4.0).

http://creativecommons.org/licenses/by/4.0/ (c) (i) Open Access

\begin{abstract}
Innovation has become an important driving force for the social development. Scientific and technological transformation gradually plays an important role in economic development, which has great significance to promote the hightechnology combined with productive forces. However, the organizations that undertake the innovation mission always don't have too much awareness of technology transformation. The efficiency of technology transformation is not high. Some universities and research agencies don't establish a reasonable and systematic transformation mechanism. Thus this paper points at the status quo and demands of university's technology transformation activities, and explores each phase of technology achievements transformation, so that some other organizations can learn from technology transformation experience, which can also provide theoretical support for the transformation of scientific and technological achievements.
\end{abstract}

\section{Keywords}

Scientific and Technological Achievements, Technology Transformation, Transformation Mechanism

\section{Introduction}

With the rapid development of science and technology around the world, the technology updating cycle is getting shorten. Scientific innovation becomes more supportive for the social development, but also a core problem in technology management, which reflects the creativity ability of different subject of tech-innovation occurs. In early 1980s, America government introduced BayhDole Act, which allowed researchers to have the patent rights to have the ownership of research achievement, promoting the commercial transformation of university and research institutes [1]. Canada also put forward various policy measures, including patent ownership, benefits right and so on, which aimed at 
maximizing the economic and social value of public-funded research activities. In Australia, the federal government has already allocated a large amount of resources to protect the commercialization of scientific and technological achievements and build university-business partnership [2]. What's more, many universities and research institutes are more interested in improving the commercialized ability themselves. China also pays much attention on technology transformation activity. The latest scientific and technological achievements transformation law (amendment) and some policies put by the state council provide the basis for technology transformation, meanwhile, the universities in our country keep learning advanced experience from foreign model, and exploring localized technology transformation model, which combined our country's situation, promoting the performance of technology transformation further [3]. So that, this paper explores the innovation model of universities' scientific and technological transformation, from the micro level to realize the operation mechanism of technological transformation, to support the technology transformation practice and promote technology management. In this paper, the researchers choose the Institute of Advanced Technology, University of Science and Technology of China as the research subject of case study, and explain the research process in details, which can show the research path and evidence clearly. In the following part, this paper would introduce the Institute of Advanced Technology firstly; and then list the research methods and collected materials to explain the research logic; at last we can make conclusions.

\section{The Situation of Universities' Technology Transformation}

\subsection{The Status Quo of Universities' Technology Transformation}

The index of national comprehensive intellectual property has steadily increased, in 2015 already reaching 187.35 point. The operating, creating, protecting level, and environment benefit are improved. Among them, university and research institute are important units to apply intellectual property of research achievements, and the proportion of intellectual property rights have been increasing year by year [4]. But compared with developed countries, the whole level of technology transformation should be improved, many research achievements are isolated from market, can't bring economic benefits, that means our research are not related with social development closely.

\subsection{Existing Technology Transformation Mechanism and Evaluations}

According to the different implementation methods, the transformation mode of scientific and technological achievements in universities can be broadly divided into direct implementation, cooperative implementation and achievements transfer. Among them, the direct implementation, namely the researcher who owns the research achievement can start his own business, or the university self-employed business to achieve the technology's economic values. Cooperative implementation means researchers cooperate with enterprise to transfer the 
research achievements together, usually use the way like stake in price, profit sharing, et al. Achievements transfer implementation is using the ownership or usage trade the benefits of commercialized achievement, let the enterprise implement the research results, including commissioned project, technology deal, et al. [5].

The methods mentioned before usually needs necessary support, always let the researcher implement the scientific and technological transformation activity voluntarily. This was called first generation of technology transformation mechanism. This model has some problems [6]. First, there is too much difference between university and enterprise, including research goal and commercial needs, innovation path, organization method, evaluation standard, even environment demands. Thus, the research achievement of universities hardly applies to the product that market needed directly. Second, the transformation mechanism of research is not systematically. The traditional system is designed to meet the needs of academic research and personnel training. The existing system has insufficient matching in the aspects of management system, department setting, incentive mechanism, et al. [7]. So that, during the real transformation process, the universities meet some obstacles generally, such as bridging with the market, product advocating and so on.

Meeting market demands is a core part to achieve commercialization of research achievements and industrialization of product. In general, university contact market very rarely, but enterprises have different mission orientation and operation style, which lead to the difference in cooperation. This caused the missing link in the technology transformation process of university, which also existing in the whole university scientific and technological industrial chain [8].

In order to solve the difficulties encountered in technology transformation, since 1980s, the government and universities explore a variety of organizational forms of innovation, such as building engineering (technology) center, technology transfer office, university science park and other forms of comprehensive technology transformation platform. Some universities even explored many other mechanisms, such as building joint research institute with enterprise, collaborative research center [9]. Part of researchers called this type of technology transformation mechanism through innovative platform scientific park model, which paralleled with traditional technology transformation model. In fact, these innovative models are based on the original transformation of scientific and technological achievements, which provide innovation platform for improving hardware and software, to bridge the industrialization and commercialization [10]. Generally speaking, the way through comprehensive innovation platform to achieve economic benefits was called the second generation of universities' technology transformation model.

After more than 20 years of exploration and practice, all kinds of innovative platforms are becoming more important in high-tech industrialization, researcher training, scientific research development, providing very good environment for enterprise, promoting the cooperation between universities and enterprise, which 
benefit for regional economic development and research achievement industrialization. But these platforms still have some problems, such as led by different departments, the guidance are not match goal, the self-evaluation is not accurate, among these, the universities research mechanism not match industrialized demands is the core reason.

In the background of the fast-paced society development, the market organization, which represented by the enterprise, encountered various market demands, complex technology environment, and has higher standard for product, service, and update. The transformation process which turn research achievement to productive forces, the whole process needs too much condition, transfer chain has many phases and each of them is interactive [11]. So that, to enhance the conversion efficiency, still needs more systematic and comprehensive exploration.

\section{Methodology and Research Objects}

\subsection{Research Methods}

This paper uses case study, mainly based on the following reasons:

1) The technology transformation research in our country still in the exploratory stage, represented by the university transformation platform, is thriving practice and very little research base, it is difficult to use traditional analysis method. Besides, technology transformation platforms meet the research standard of extremely research sample, belongs to the scope of case study. Thus using case study can explore new information of thriving stuff, proving the first hand information for the study [12].

2) Technology transformation related with interaction of different objects, focus on process study. Case study method is dynamic, could track, describe, and evaluate stuff better, more suitable for process-oriented research issues.

3) The technology transformation problem is highly complex, the concept has been put forward for long periods, but researchers still can't understand the potential mechanism. What's more, the subjects of this research field are too many, including the personal behavior of micro level to scientific policy making of macro level. The case study is suitable for complicated problems, the case study method has the characteristics of embedded and inner perspective, and can study the essence of the problem in depth.

In case study, this paper adopts the methods of interview, observation, physi$\mathrm{cal}$ analysis and document analysis, to construct triangle evidence from multiple sources and perspectives. Interview, which means at least two researchers to access to the worker in this institute, and one listed some relevant questions, the other is responsible for noting words, during the interview, the researcher can observe the facial expression of interviewee, to make sure the information is true. Physical analysis, to examine whether the material is match the interview information or document information or not. Document analysis is collecting related policy, regulation, conference notes et al., to verify the situation of the institute whether match the planning document. 


\subsection{Research Objects}

This paper chooses Institute of Advanced Technology, University of Science and Technology of China, which referred as institute of advanced technology, as research objective. The main reason as follows:

1) Institute of advanced technology was the earliest established professional technology transformation platform, also one of the few platforms already in operation. Thus it can be seen as a strong individualized case, in line with the scope of the case study.

2) Institute of advanced technology is responsible for technology transformation, combined with research and market. Institute of advanced technology is depending on university of science and technology of China, thus own much high quality intellectual property, the operation behavior is typical.

3) The history of institute of advanced technology is not long (established in 2012), the operation model is different with traditional incubator and scientific park, but has its own characteristics. Besides the institute has policy support, it's more inclined to adopt new policy, and has certain priority trial rights, with good external conditions.

Before conducting research and in-depth study, researchers try to realize objects firstly, using network, phone call to collect part files. Based on the realized survey information to sort out a clear outline, mainly for the investigation before the field survey and track important stuff, and add detail information to outline after investigation. As shown in Figure 1.

\section{A: preparation: case and files}

1. The background of high-tech transformation
a) Social factor
b) Research factor
c) Cultural factor

2. The background of constructing technology transformation platform in university
a) introduction of university
b) department management
c) management model

3. The measures of technology transformation

4. Implementation and feedback
a) choose implementation methods
b) tracking
c) feedback and evaluation

5. Attribution analysis
a) factor analysis
b) risk analysis
c) technology analysis
d) market analysis

Figure 1. Case outline (part of research). 


\section{The Situation of Technology Transformation of Institute of Advanced Technology}

\subsection{Status of Institute of Advanced Technology}

The Institute of Advanced Technology was built by Anhui province, Hefei city, the Chinese academy of science and USTC, based on the principle of collaboration between province and academy, municipal and university. Different from the nature of incubator and university science park, the Institute of Advanced Technology is a public institution, which burden the benefits and the loss itself. The main task is to carry out high-tech R \& D and application, also high-tech researcher training, is a very important part in creating a world-class researchoriented university, is an extension of teaching and research system. The main purpose is based on basic research achievements of USTC, gradually improve the level of research industrialization. The institute was charged in bringing the technology with market potential, providing very good environment and preferential business conditions, such as the provision of registered address, free of rent for a year, and ultimately guide the development of technology mature and extended to the market.

The Institute of Advanced Technology has more than thousand acres, is in the first phase of construction. Now, it has management staff 32, more than 400 researchers, and 400 graduate students. And it already adjusts the department, now has four, respectively technology development department, which undertake the technology development work and service function, based on university, research academy to build a new platform which apply for second innovation of technology and experience trial. Combing with development needs of society, the department provided high-tech for industrialization. Second, enterprise development department, which is responsible for development plan and annual work plan, application for intellectual property and protection. Third, information technology department, the main job is advocating the news, cultivating the internship, and education. Forth, service management department, responsible for staff recruitment, finance, and material, and daily administration and publicity work. The Institute of Advanced Technology creates academy and platform model, expand the way of technology transformation, enhance the advantages of technology transformation.

\subsection{Data Collection and Processing}

In order to gain a better understanding of the operation mechanism and model, from June 2015 to June 2016, the researcher interviewed the worker in The Institute of Advanced Technology many times, and visited the institute. The relevant personnel including engineers, technology worker, and management staff. During the interview, at least two people at the scene, one people conduct the conversation, the other one is responsible for recording and observation. After the interview is over, the researchers would leave the place very soon, in order to keep the mind objectively and independently. After that, the researchers would analyze the information, and using the software called Nvivo to manage the files, 
to build the Nvino database. Also keeping updating the information collected, add secondary code and third code, such as researchers, benefits allocation, and introduced project, and construct the connection between different codes. Meanwhile, based on the connection, the researchers assume the causal link between variables. Besides, the researchers also scan the websites of government to collect related data, make full preparation for research.

\section{The Framework of Case Study}

As the transformation of scientific and technological achievements in the community has aroused too much attention, many scholars realize the significance of technology transformation. But the related research on this field just based on theoretical construction and the introduction of foreign models, and little research on domestic practical model. Based on the previous research, this paper focuses on the question of whether there are any exploratory innovations in the transformation of scientific and technological achievements in domestic universities, the transformation mechanism of scientific and technological achievements in domestic universities, and the marketing of scientific and technological achievements, which provide a new research direction and research path. so this study is a type of phenomenon-driven Thus, pointing at the process of the Institute of Advanced Technology, divides the transformation mechanism of scientific and technological achievements into the project mechanism, the operation mechanism and the marketing mechanism, and analyzes the mode of transformation of scientific and technological achievements, and experience (mechanism flow chart, see Figure 2).

\subsection{Research Project Funding Mechanism}

The project funding mechanism, namely the innovation target located of research, to bridge the local market. In the pre-phase, the subject should ensure the potential of research project, this mechanism includes two, dual leadership of strategic level and specialists' consultation of project level.

1) Dual leadership consultation mechanism

As mentioned above, the Institute of Advanced Technology is built by four different subjects, in order to facilitate coordination and communication, it adopted dual leadership mechanism, each level of leaders of institute are also in the government, academy, and USTC. When faced with majority problems, they usually have consultation and operation, and make decision jointly. Compared with other organizations, the Institute of Advanced Technology is relatively neutral. This information got by interview, and checked with other people worked in the institution. Thus this information is considered to be real and reliable. The researcher listed the name of interviewed people and some documents also confirm the statement, shown as Table 1 and Table 2.

2) Expert consultation mechanism

At the project level, the Institute of Advanced Technology will choose qualified project. The general process is to convene the experts to discuss the feasibi- 


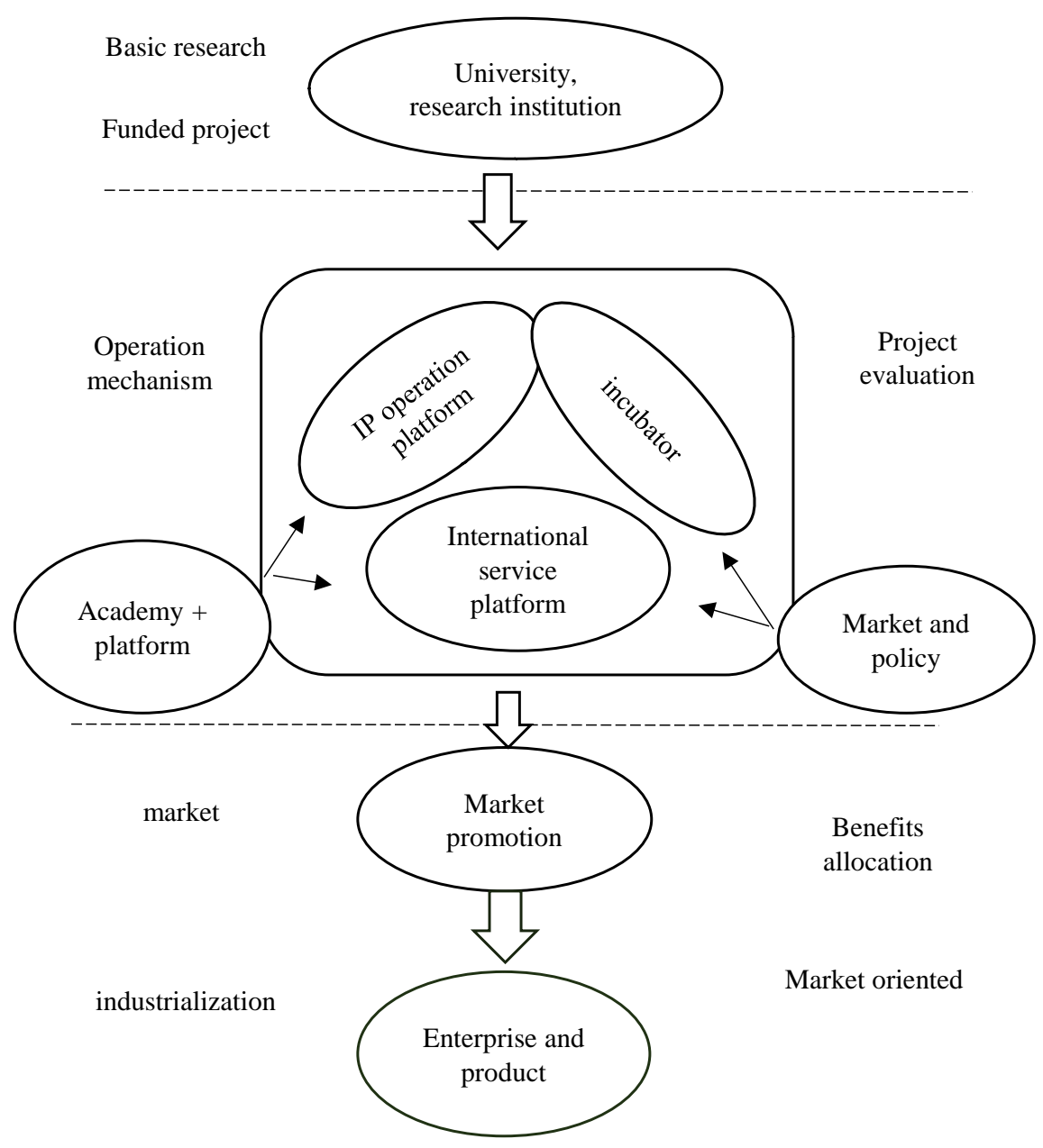

Figure 2. The technology transformation mechanism of the institute of advanced technology.

Table 1. The sequence of role: the reaction to the institute management.

\begin{tabular}{ccccc}
\hline Platform & Interview & Position & $\begin{array}{c}\text { Related with } \\
\text { management }\end{array}$ & Attitude \\
\hline $\begin{array}{c}\text { Microelectronics } \\
\text { and optoelectronic } \\
\text { common }\end{array}$ & A & deputy chief engineer & closely & positive \\
$\begin{array}{c}\text { technology platform } \\
\text { Management }\end{array}$ & C & engineer & medium & medium \\
$\begin{array}{c}\text { International } \\
\text { R \& D service } \\
\text { outsourcing }\end{array}$ & D & person in charge1 & closely & closely \\
innovation platform & F & person in charge 2 & medium & medium \\
$\begin{array}{c}\text { Technology } \\
\text { management } \\
\text { department }\end{array}$ & G & person in charge & medium & medium \\
\hline
\end{tabular}


Table 2. Relevant documents source of evidence.

\begin{tabular}{|c|c|}
\hline Type of evidence & Source of evidence \\
\hline Document & $\begin{array}{l}\text { Internal management practices, management manuals, etc., } \\
\text { affiliated platform regulations, regulations and other documents. }\end{array}$ \\
\hline File & $\begin{array}{l}\text { Regulations in the website of government, } \\
\text { news of related government department. }\end{array}$ \\
\hline Observation & $\begin{array}{l}\text { Major events are held jointly by both parties, and management } \\
\text { personnel are present, and some documents are signed by both managers. }\end{array}$ \\
\hline
\end{tabular}

lity of the project transformation and promotion in the form of a conference. According to the advantages of the Institute of Advanced Technology, the researchers here can have good interaction, choose project that match the character of the institute. Researchers interviewed the related worker to confirm the information and introduced the process specifically. Besides, researchers found that the most of funded projects are in material and agriculture fields, little in internet product, the researcher think that it mainly because the institute depends on the advantage of USTC, and the internet marketing is already developed, although the periods are short, but it need too much invest. Thus the Institute of Advanced Technology chooses to combine with the research background. Researcher observed the enterprise in the institute, found rarely related internet product, almost in material, computer and other content-based, from the side confirmed that the experts' database is building, and evaluating the project funding. The process of collecting data, the researchers used the methods of interview, observation and evidence of things, confirming the operation mode and authenticity of this mechanism from various aspects, and constructed the role sorting table and test table (seen as Table 3), researchers for the interview object using a pseudonym:

By comparing the expert database to the project metrics and evaluating the responses to the relevant audiences, it is possible to understand the needs of the audience in timely and to identify the needs of the market. On the one hand, it can assess the professionalism and fairness of the expert database, and can be timely to find social concerns to understand the project incubation innovation and flexibility, for the first Institute of project evaluation expert database construction can be relatively comprehensive evaluation.

\subsection{Technology Transformation Operation Mechanism}

Economist Schumpeter pointed out that innovation, including technological innovation and institutional innovation, if countries or enterprises to achieve sustainable development, must be at the same time technological innovation and institutional innovation. Only technical innovation, there will be "lock-in" effect. In the process of independent innovation, people tend to pay great attention to technological innovation, while ignoring the importance of institutional innovation. At present, one of the problems in the transformation of scientific and 
Table 3. Reaction to incubation project.

\begin{tabular}{|c|c|c|}
\hline $\begin{array}{l}\text { Factor analysis of } \\
\text { incubation project }\end{array}$ & Attitude of expert & $\begin{array}{l}\text { Attitude of related } \\
\text { technology group }\end{array}$ \\
\hline Technology & $\begin{array}{l}\text { Whether technical innovation } \\
\text { is mature, can achieve the } \\
\text { completion of the sample, } \\
\text { the function is consistent. }\end{array}$ & $\begin{array}{c}\text { Whether the technology can } \\
\text { arouse the audience's interest, } \\
\text { whether to recognize } \\
\text { the innovation. }\end{array}$ \\
\hline Understand & $\begin{array}{l}\text { Whether the expert's understanding } \\
\text { of the technology is, whether it is } \\
\text { a comprehensive assessment } \\
\text { of the meaning of technology. }\end{array}$ & $\begin{array}{l}\text { Whether to understand the } \\
\text { meaning of the } \\
\text { technological innovation. }\end{array}$ \\
\hline Prospect & $\begin{array}{l}\text { Whether the technology has a } \\
\text { good industrial prospects, } \\
\text { bring the expected benefits. }\end{array}$ & $\begin{array}{l}\text { Whether the target group } \\
\text { expects the technology } \\
\text { to be industrialized. }\end{array}$ \\
\hline Time period & $\begin{array}{l}\text { The product's time-cycle } \\
\text { assessment is related to the risk } \\
\text { of technology investment. }\end{array}$ & $\begin{array}{c}\text { Whether to recognize } \\
\text { the cycle of } \\
\text { technological industrialization. }\end{array}$ \\
\hline Funding invest & $\begin{array}{l}\text { Whether the industrialization } \\
\text { requires a lot of } \\
\text { capital investment. }\end{array}$ & $\begin{array}{l}\text { Whether it is recognized } \\
\text { as a high capital investment } \\
\text { and output model. }\end{array}$ \\
\hline $\begin{array}{l}\text { Related with } \\
\text { management }\end{array}$ & $\begin{array}{l}\text { Whether it can rely on the } \\
\text { faculties of the disciplines } \\
\text { and technical advantages. }\end{array}$ & $\begin{array}{l}\text { And whether the combination } \\
\text { of the advantages of the academy } \\
\text { has become a screening } \\
\text { index of the project. }\end{array}$ \\
\hline
\end{tabular}

technological achievements in China is that there is no in-depth study on the transformation mechanism, and most of them are in the theoretical discussion. Therefore, constructing the transformation mechanism of scientific and technological achievements, to open the black box of transformation process, become a majority work in technology transformation. There are two parts in technology transformation of the Institute of Advanced Technology. One is managed by the management of institute directly, the other is indirectly way, the institute hold the stake of the independent department. From these two ways of operation, we can see the institute use academy plus platform model, it uses both enterprise and publicity unit model.

Intellectual property operation platform is very important in the Institute of Advanced Technology. The reason is that the institute undertakes a Torch Plan, from January 2016 to December, lasting one year. It has three stages: first, building a trading platform, "for the region's intellectual property trading platform", to undertake the school's scientific research, under the enterprise's investment and financing, the main transformation methods are three: License (charge), transfer (sell), price investment (derivative). Mainly based on intellectual property is a property that can bring benefits. The initial use of patent results investment, scientific research into the project, through the project to attract business participation, gathering, the ultimate goal is to form an industry. The ideal goal is to establish a university research achievement-technology 
transformation platform-financial invest system. Second, international construction, platform and the French Patent Sovereign Fund (FB) cooperation, through the national background and channels to set up cooperation office, the introduction of talent and foreign experience, the final project landing. In addition, learn international practices and rules, fight against patent rogue, protect reasonable intellectual property rights. Third, researchers want to deepen the patent application, the establishment of technical professional office (TTO), to create a technical background, legal background, business background as an integrated platform, and specifically deal with patent value assessment, transformation and other issues. The final results of the Torch Plan mainly include two aspects: one is having physical sites, build online and offline platform, the other is that, in the platform on the basis of the completion of several project transactions. The construction of the intellectual property operation platform is a good way to make up for the domestic colleges and universities do not understand the operation of the intellectual property market, providing a patent into the finished product and the market after the street. Through the intellectual property operation platform, you can set up enterprises or the introduction of capital, the prospects of better product incubation to the market, access to good industrial prospects and market returns.

Researchers focused on the incubated project in the Institute of Advanced Technology, and kept long consistent and observation, they saw the research achievements of color detectors, led AC drive and thin film technology. These patents are the core part of photovoltaic agricultural technology. The color detector can distinguish red light and blue light, and can adjust the proportion of the light. Led AC drive is opposed to DC drive, it can improve the efficiency of energy use, the maximum can up to $20 \%$. The thin film technology can filter can the red light and blue light, and reflecting the red light. Thus the red light can be used for power generation, and blue light used for plant growth. Researcher googled the related patented websites and found more than ten intellectual properties was approved. After testing the technology, the PV is currently developing into the experimental stage to design the final product. At present, the PV agriculture project team has built a trial area of 36 square meters to carry out small-scale agricultural planting and power generation work. Researchers conducted field tests on the test fields and obtained first-hand information. In addition, in the IP project platform to promote the stage of PV agriculture project, the Institute of Advanced Technology wants to create a company to implement the patent, this is consistent with interviewed information. Also the researchers found that the PV agricultural project team to participate in entrepreneurial competition and won some startup company competition awards. It could confirm the words. The According to the research data and the process of project transformation, the key events and the timeline of the transformation of PV agriculture are formulated, as shown in the following table (shown as Table 4). The researchers sort out the patent applied timeline, combined with materials to check whether the information is true, ensuring the information is effective. 
Table 4. Majority events and timelines.

\begin{tabular}{c}
\hline 2011.11-2012.10 PV agricultural intellectual property, and the team into the institute. \\
2012.12 $\begin{array}{r}\text { Theoretical test, prepare for design the trial sample. } \\
\text { Team to participate in entrepreneurial, } \\
\text { to attract social concern, won the Gold Award. } \\
\text { Explore the results of the transformation of cooperation, } \\
\text { including entrepreneurship and revenue. } \\
\text { Set up a prototype, begin test field. } \\
2015.5 \\
2016.3\end{array} \quad$ Start up company, finished the test field, evaluate the practice. \\
\hline
\end{tabular}

Until the sample is mature, the transformation of scientific and technological achievements into the interface with the market, the important parts are product performance, intellectual property rights and other issues and how to carry out marketing. As the establishment of the Institute of Advanced Technology is short, the main attention on material, computer technology field, the technology transformation period lasted too long, and many intellectual property platforms are not into the market. Thus in this article, focusing on two issues, one is the proportion of benefits distribution of scientific and technological achievements, and the other is the analysis of the market promotion mechanism of scientific and technological achievements. In the latest scientific and technological achievements transformation law, and the State Council put forward some policies rule that the researcher can have at least $50 \%$ proportion of benefits, the Institute of Advanced Technology already improved the benefits allocation proportion up to $50 \%$, and inner brochure of the institute to confirm the rule. Also researchers found the original intellectual property of the Institute of Advanced Technology and confirm the regulation. During the survey process, researcher made a conclusion that the benefits allocation would not be a problem in the technology transformation. The other research question of this paper is professional market promotion mechanism. In domestic, the scholars are not having too much research achievements, just on theoretical level. the Institute of Advanced Technology mainly rely on the affiliated platforms and cooperate with foreign organization, setting independent office in foreign countries, introduce and learn professional intellectual property talents, which promote the commercialized process of technology transformation. During the investigation, the operation platform still under construction, researchers just found some planning documents, so researchers wish to explore more in the future research, to open the black box in technology transformation, to ensure the continuity of the technology transformation. Based on the existing research achievements, researcher constructs a technology transformation mechanism of the Institute of Advanced Technology, such as Figure 3.

This mechanism analyzes the driven factor of technology transformation, and then through constructing company, stake shares and enter into the market ultimately. During this process, it combined with open innovation paradigm and found new path to promote the research achievements, link research achieve- 


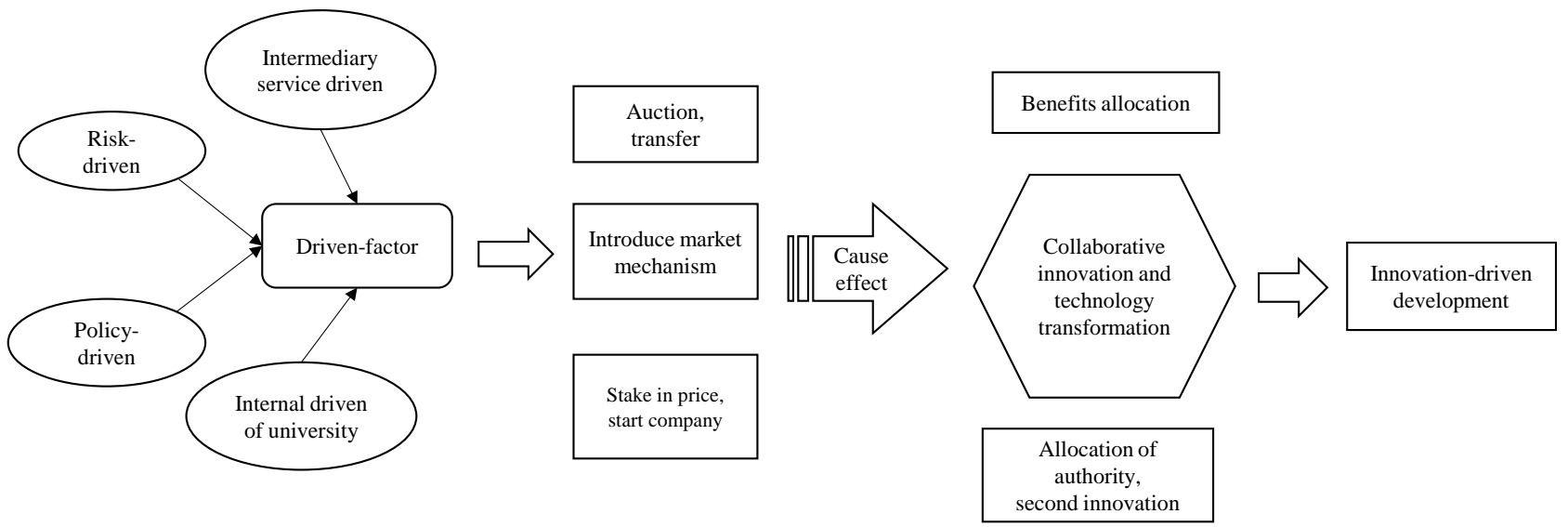

Figure 3. The technology transformation of the institute of advanced technology.

ments with social development, and ultimately achieve innovation-driven development.

\section{Conclusions and Suggestion}

In order to further promote the innovation-driven development, it is necessary to seek a new growth point of national economic development, and make the research more realistic; and university in domestic should explore the technology transformation model more positively. As a representative of technology transformation, the Institute of Advanced Technology will play its own advantages and actively explore the multi-participant mechanism under the environment, and achieve remarkable results.

In the technology transformation field of university and research institute, the Institute of Advanced Technology on the basis of accumulated experience actively learns from foreign advanced models and practices, to explore the localized technology transformation model. To solve the problems of traditional universities' technology transformation, using innovation target, operation mechanism and market promotion, and developing relatively comprehensive technology transformation service and industrial chain are regarded as the second generation of domestic universities' technology transformation mechanism. The Institute of Advanced Technology relying on the education resource of USTC and its own advantages, will concentrate more on market, and will cultivate a batch of famous companies. Through international and cooperation, the Institute of Advanced Technology will train more technician and specialist, promoting the regional development. In the context of the national reform and economic transformation, the technology transformation platforms will play more important role in social development and promoting the local industry updating, which also contribute to the construction of national innovation system. In order to further improve the technology transformation mechanism of the Institute of Advanced Technology, improving the performance of technology transformation and innovation ability, this paper put forward the suggestions as followings: 
1) Enhancing the policy support, improving benefits allocation mechanism. The Institute of Advanced Technology can strengthen the policy support and enhance the innovation enthusiasm of the scientific and technological workers in the existing framework and policy. In the projects involving intellectual property rights, the ownership of intellectual property rights can be reformed and the ownership of intellectual property rights can be delegated to researchers in the form of gifts and rewards [13]. At the same time, the institute should improve the benefits allocation mechanism of technology transformation, and make a reasonable reward standard to protect the legal rights of researchers' benefits [14].

2) Strengthen international cooperation and professional personnel training. On the basis of making full use of its own advantages, the Institute of Advanced Technology should cooperate with foreign intellectual property operation platform, introduce professional intellectual property operation personnel, and construct the international transformation mechanism of intellectual property rights [15]. At the same time, the Institute of Advanced Technology should cooperate with USTC and top-class universities and enterprise, which is helpful to the shortage of professional talents, also helpful to enhance the level of scientific and technological achievements.

3) Actively introduce the market mechanism, promote the marketization of scientific research. Technological innovation and social needs are closely linked, and the research achievements should turn into productivity forces through the market mechanism, it's meaningless that if the research achievements are not linked with society needs [16]. Thus, the Institute of Advanced Technology should encourage the affiliated platforms enter into market, choose high-quality project, reduce the dependency of government, and related government departments' intervention. Combined the research achievements with market demands, the technology transformation platform would promote the competitive advantage of lab technology, and make more contributions to the social development.

\section{Funding}

This research is supported by the funding in the background of "the belt and road" the online education international corporation research of China, which funded by online education fund (Quantong Education), Online Education Research Center in Ministry of Education. Funding number: 2017ZD110, project duration: 2017.1.1-2018.12.31.

\section{References}

[1] Grimaldi, R., Kenney, M., Siegel, D.S., et al. (2011) 30 Years after Bayh-Dole: Reassessing Academic Entrepreneurship. Research Policy, 40, 1045-1057.

[2] Aldridge, T.T. and Audretsch, D. (2011) The Bayh-Dole Act and Scientist Entrepreneurship. Research Policy, 40, 1058-1067.

[3] Jia, J., Zhao, L., et al. (2015) A Comparative Study on the Transformation of Scientific and Technological Achievements from China to Foreign Countries. Science and Science and Technology Management, No. 7, 3-10. 
[4] Zhang, S. and Guo, Y. (2014) Solving the State-Owned Scientific Research Institutions Scientific and Technological Achievements into Institutional Barriers. China Science and Technology Forum, No. 8, 36-41.

[5] Zhao, J., et al. (2011) Research on Technology Shares in the Transformation of Scientific and Technological Achievements. Science Research, No. 10, 1485-1489.

[6] Hu, G., et al. (2014) Local Research Institute: A New Exploration of the Transformation Model of Scientific and Technological Achievements in Universities. Research and Development Management, 26, 122-128.

[7] He, D. (2011) Analysis and Reflection on Some Basic Concepts of Scientific and Technological Achievements and Transformation of Scientific and Technological Achievements. China Soft Science, No. 11, 1-7.

[8] Yang, S., et al. (2013) Technology Transfer and Scientific and Technological Achievements into the Understanding and Comparison. China Science and Technology Forum, No. 12, 116-122.

[9] Cai, Y. (2015) The Connotation of the Transformation of Scientific and Technological Achievements and Statistical Measures. Science Research, 33, 37-43.

[10] Wang, H. and Zhang, Y. (2013) Research on the Mode of Local Economic Development of University Technology Transfer Center. Technology and Management, No. 4, 132-138.

[11] Huang, C. (2011) Study on the Transformation Mechanism of American Scientific and Technological Achievements. Hubei Social Sciences, No. 10, 81-84.

[12] Eisenhardt, K.M. and Graebner, M.E. (2007) Theory Building from Cases: Opportunities and Challenges. Academy of Management Journal, 50, 25-32. https://doi.org/10.5465/AMJ.2007.24160888

[13] Yang, X. and Yu, B. (2012) The Choice of the Transformation Model of Scientific and Technological Achievements in China. Learning and Exploring, No. 8, 106-108.

[14] Sun, W., et al. (2009) Institutional Innovation of Cooperative Mode of Production, Teaching and Research: Comprehensive Innovation. Research on Scientific Research Management, 30, 69-75.

[15] Liu, Z. and Li, D. (2013) On the Organization of Scientific and Technological Achievements in Colleges and Universities. Science and Technology Information, No. 5, 28-29.

[16] Wang, H. and Zhang, Y. (2013) Research on the Mode of Local Economic Development Serving the Technology Transfer Center in Universities. Technology and Management, 15, 132-138. 
Submit or recommend next manuscript to SCIRP and we will provide best service for you:

Accepting pre-submission inquiries through Email, Facebook, LinkedIn, Twitter, etc. A wide selection of journals (inclusive of 9 subjects, more than 200 journals)

Providing 24-hour high-quality service

User-friendly online submission system

Fair and swift peer-review system

Efficient typesetting and proofreading procedure

Display of the result of downloads and visits, as well as the number of cited articles Maximum dissemination of your research work

Submit your manuscript at: http://papersubmission.scirp.org/

Or contact jss@scirp.org 